\title{
Adsorption of Nutrients from Stormwater Using Sawdust
}

\author{
K. D. Harmayani and A. H. M. F. Anwar
}

\begin{abstract}
This study investigates the adsorption characteristics of sawdust for removing nutrients (e.g., $\mathrm{NH}_{3}-\mathrm{N}$, $\mathrm{NO}_{3}-\mathrm{N}$, and $\mathrm{NO}_{2}-\mathrm{N}$ ) from stormwater. A series of laboratory batch experiments was performed and the effects of different parameters on nutrient adsorption were observed. The parameters of concern include: initial concentration $(0.5-5 \mathrm{mg} / \mathrm{L})$ and dosage (2-20mg of dry sawdust). Results revealed that the maximum removal was obtained at lower initial concentration. An increase of adsorbent dosage increased the percent removal of $\mathrm{NH}_{3}-\mathrm{N}, \mathrm{NO}_{3}-\mathrm{N}$, and $\mathrm{NO}_{2}-\mathrm{N}$. The maximum removal of $\mathrm{NO}_{3}-\mathrm{N}$ and $\mathrm{NO}_{2}-\mathrm{N}$ was found $100 \%$, while $\mathrm{NH}_{3}-\mathrm{N}$ removal was found $55 \%$. The sorption of sawdust was characterized by Langmuir and Freundlich isotherm and the results show that the correlation coefficient of applicability $\left(\mathbf{R}^{2}\right)$ of Freundlich model $\left(R^{2}=0.8324,0.9856\right.$, and 0.9231 for $\mathrm{NH}_{3}-\mathrm{N}, \mathrm{NO}_{3}-\mathrm{N}$ and $\mathrm{NO}_{2}-\mathrm{N}$ respectively) fits better than Langmuir $\left(R^{2}=0.7963,0.9751\right.$, and 0.8049 for $\mathrm{NH}_{3}-\mathrm{N}, \mathrm{NO}_{3}-\mathrm{N}$ and $\mathrm{NO}_{2}-\mathrm{N}$ respectively).
\end{abstract}

Index term-Adsorption, equilibrium isotherm, nutrients removal, sawdust.

\section{INTRODUCTION}

Ammonia $\left(\mathrm{NH}_{4}+\right)$, nitrate $\left(\mathrm{NO}_{3}^{-}\right)$, and nitrite $\left(\mathrm{NO}_{2}^{-}\right)$are inorganic nitrogen commonly found in urban stormwater runoff [1]. These compounds are normally resulted from auto emissions, fluid leaks from vehicles, home use fertilizer and pesticides, refuse, and pet feces. These pollutants in stormwater have adverse effects on groundwater quality especially in urban areas [2] which is also responsible for eutrophication problem in receiving water [3].

These nutrients have harmful effects on human health and overall ecosystem. Although nitrate is fairly non-toxic, but when it transform to nitrite, which combines with hemoglobin in the blood to form methemoglobin, it might have risk in infant's body called methemoglobinemia also known as "blue-baby syndrome" a situation of oxygen deficiency [4]. There is incidental confirmation linking nitrite in leading to cancer risk [5]. Thus, the maximum contaminant levels of $\mathrm{NO}_{3}{ }^{-}-\mathrm{N}$ and $\mathrm{NO}_{2}{ }^{-}-\mathrm{N}$ are set as $10 \mathrm{mg} / \mathrm{L}$ and $1 \mathrm{mg} / \mathrm{L}$ for drinking water respectively [6].

Bioretention systems are commonly used for removing the inorganic nitrogen from stormwater [7-10]. The use of different sorption media in this system is the most daunting task to select. Using renewable resources for contaminant removal through adsorption is becoming more cost-effective method. Some materials have been tested for this purpose, such as sepiolite [11], bittern [12], clinoptilolite [13-14],

Manuscript received January 29, 2012; revised March 7, 2012.

K. D. Harmayani is $\mathrm{PhD}$ candidate at Civil Engineering, Curtin University, Western Australia (e-mail: kadekdia@student.curtin.edu.au).

A. H. M. F. Anwar is Senior lecturer at Civil Engineering, Curtin University, Western Australia (e-mail: F.Anwar@curtin.edu.au). hardwood mulch [15], and sawdust [16-18].

All researchers were mixing sawdust with other green sorption media. Xuan (2010) studied a mix of selected media consisted of $68 \%$ fine sand, $25 \%$ tire crumbs, and $7 \%$ of sawdust. They used less than $10 \%$ of sawdust in their adsorption media for supporting denitrification. If part of the medium becomes anaerobic, in that case, sawdust acts as an electron donor. They investigated that $96 \%$ of nitrates were removed during 24 hours of shaking time which followed by 24 hours of anaerobic period [17]. Whereas Hossain [18] mixed $50 \%$ sand, $20 \%$ limestone, $15 \%$ sawdust, and $15 \%$ tire crumb in their experiments. They concluded that the filter media mixture was efficient and effective for the removal of nitrate and nitrite at lower concentration. The highest removal efficiency was reached at $95.36 \%$ with $0.5 \mathrm{mg} / \mathrm{L}$ influent of nitrate after 5 hours of hydraulic retention time. Nitrite was reached $98.72 \%$ removal efficiency with 2.5 $\mathrm{mg} / \mathrm{L}$ of nitrite and $100 \%$ removal efficiency for ammonia with both waste load concentration of 0.5 and $2.5 \mathrm{mg} / \mathrm{L}$ after 1 and 1.5 hours hydraulic retention time [18]. Kim [16] selected the different material as potential electron donors to treat stormwater. They performed three sets of experiments: (i) Set 1 consisted of alfalfa, newspaper, and leaf mulch compost, (ii) Set 2 consisted of sawdust, wood chips, and wheat straw, and (iii) Set 3 consisted of small sulfur-limestone, large sulfur-limestone, and large sulfur only particles. They found that in experimental set $1,100 \%$ nitrate removal was observed in the alfalfa and newspaper column. In set 2, the sawdust, wheat straw, and wood chips columns were achieved greater than $95 \%$ nitrate removal. The small sulfur-limestone column, in set 3, was attained 91\% nitrate removal. Based on these results, they chose newspaper, wood chips, and small sulfur-limestone as the best electron donor for their further experiments. In experimental set 2 , because of wood chips showed better removal of nitrate along the column length (data not shown), they opted wood chips rather than sawdust [16].

There is a very limited literature explaining the mechanism of adsorption on sawdust solely in stormwater. Since sawdust is abundant, inexpensive and unused resources from agricultural byproduct, the use of this material would be beneficial for both the environment and wood agriculture: polluted streams would be cleaned and a new market would be opened for the sawdust. Sawdust from radiata pine contains cellulose, lignin, and tannins or other phenolic compounds which are active ion exchange compounds [19].

The main objective of this study is to investigate the removal efficiency and modes of surface coverage of sawdust for the removal of inorganic nitrogen from synthetic stormwater and to examine the adsorption isotherm models which best describe the experimental data. 


\section{MATERIALS AND METHODS}

\section{A. Materials and Equipments}

The sawdust of Radiata pine wood was taken from Stokic Nominees, a wood manufacturing company at Maddington Western Australia. Manufacturer confirmed that the radiata pine wood was not chemically treated and the sawdust was free from any chemicals. To remove the dust and any possible nutrients, sawdust was washed with distilled water. After each washing, $2 \mathrm{ml}$ water from effluent was taken and filtered for nutrients analysis. After 6 to 7 times washing, nutrients contain in sawdust became nil. The wet sawdust was oven dried at $105^{\circ} \mathrm{C}$ for $24 \mathrm{hrs}$ and then stored at room temperature $\left(22 \pm 2^{0} \mathrm{C}\right)$.

All chemicals used in the experiments were analytical grade and purchased from Thermo Fisher Scientific, Sydney, Australia and solutions were prepared with deionised water. The stock solution of ammonia-nitrogen $\left(\mathrm{NH}_{3}-\mathrm{N}\right)$, nitrate-nitrogen $\left(\mathrm{NO}_{3}-\mathrm{N}\right)$, and nitrite-nitrogen $\left(\mathrm{NO}_{2}-\mathrm{N}\right)$ solution were prepared from $\mathrm{NH}_{4} \mathrm{Cl}, \mathrm{NaNO}_{3}$, and $\mathrm{NaNO}_{2}$ respectively. New solutions were prepared before each experiment to avoid any possible contamination. The $\mathrm{pH}$ measurement was performed using $\mathrm{HACH}$ portable $\mathrm{pH} /$ temp meter (accuracy \pm 0.1 ). The concentration of $\mathrm{NH}_{3}-\mathrm{N}, \mathrm{NO}_{3}-\mathrm{N}$, and $\mathrm{NO}_{2}-\mathrm{N}$ were determined using AQUAKEM 200 water analyzer. The accuracy of the analysis was $\mathrm{NH}_{3}( \pm 0.015)$, $\mathrm{NO}_{3}( \pm 0.02)$, and $\mathrm{NO}_{2}( \pm 0.015)$.

\section{B. Batch Experiments}

Batch experiments were carried out for different initial concentrations and dosages. First, 20 gram of dry sawdust $(300 \mu \mathrm{m}-600 \mu \mathrm{m})$ was poured into Erlenmeyer flask and 200 $\mathrm{ml}$ water solution of desired concentrations ( $\mathrm{pH} \mathrm{6-7)}$ was taken into the flask. The top of each flask was wrapped using parafilm to avoid evaporation. The Erlenmeyer flasks were kept on a shaking platform (Innova 2000, New Brunswick Scientific) with $100 \mathrm{rpm}$ at room temperature $\left(22 \pm 2^{0} \mathrm{C}\right)$. The time required for getting the equilibrium condition was estimated by taking a $5 \mathrm{~mm}$ samples until equilibrium was reached. All samples were tested after passing through filter syringe size of $0.45 \mu \mathrm{m}$. Next, dosages tests were performed. In this research, a range of dosages (2-20 gram of sawdust) was considered and a known concentration of adsorbate solution (1 mg/L, pH 6-7) was prepared from stock solution. Two hundred milliliter of this solution was transferred into each flask.

The percent adsorptions are calculated as [20]:

$$
\operatorname{Re} \operatorname{moval}(\%)=\frac{\left(C_{i}-C_{f}\right)}{C_{i}} 100
$$

where $C_{i}$ and $C_{f}$ are the initial and final nitrogen concentrations respectively

\section{Adsorption Isotherms}

Langmuir and Freundlich isotherm models are applied to fit experimental data. The Langmuir model is used to illustrate the equilibrium between surface and solution as a reversible chemical equilibrium between species [21]. This model can be written as [20]:

$$
\frac{C_{e}}{q_{e}}=\frac{C_{e}}{q_{m}}+\frac{1}{q_{m} K_{L}}
$$

where, $C_{e}$ is equilibrium concentration of nitrogen solution $(\mathrm{mg} / \mathrm{L})$ and $q_{e}$ is the amount of nitrogen adsorbed $(\mathrm{mg})$ per unit of sawdust (g). $q_{m}$ and $K_{L}$ are Langmuir constant relating adsorption capacity $(\mathrm{mg} / \mathrm{g})$ and the energy of adsorption

$(\mathrm{L} / \mathrm{g})$, respectively. The Langmuir isotherm is obtained by plotting a graph between Ce/qe and $\mathrm{Ce}$.

Based on the additional analysis of Langmuir equation, the dimensionless parameter of equilibrium or adsorption intensity $\left(R_{\mathrm{L}}\right)$ can be expressed by [20]:

$$
R_{L}=\frac{1}{1+K_{L} C_{O}}
$$

where $C_{0}(\mathrm{mg} / \mathrm{L})$ is the initial quantity of adsorbate. The $R_{\mathrm{L}}$ parameter is considered more reliable indicator of adsorption: (i) $0<R_{\mathrm{L}}<1$ indicates favorable adsorption, (ii) $R_{\mathrm{L}}>1$ indicates unfavorable adsorption, (iii) $R_{\mathrm{L}}=1$ indicates linear adsorption, and (iv) $R_{\mathrm{L}}=0$ indicates irreversible adsorption.

Next, the adsorption data were fitted for Freundlich isotherm. The Freundlich isotherm is applied for non ideal sorption on heterogeneous surface and multilayer sorption such as activated carbon [21]. Freundlich model is expressed in linear form [18]:

$$
\log q=\log K+\frac{1}{n} \log C
$$

where $K(\mathrm{mg} / \mathrm{g})$ and $\mathrm{n}$ are constants involving adsorption capacity and adsorption intensity respectively. These constants are determined from the intercept and slope of linear plot of $\log q$ versus $\log C$ respectively.

Both isotherms were compared for the correlation coefficient of applicability $\left(\mathrm{R}^{2}\right)$, whether following Langmuir model as monolayer surface coverage or Freundlich model which is signify of heterogeneous surface coverage.

\section{RESULTS AND DISCUSSION}

\section{A. Effect of Concentrations}

The effect of initial concentration on the removal of nitrogenous compounds from stormwater is checked and shown in Fig.1. The percentage removal of ammonia-nitrogen was found higher in lower concentrations. The maximum removal $(60 \%)$ was obtained at $1 \mathrm{mg} / \mathrm{L}$ within 15 minutes. The adsorption rate gradually decreased with increasing concentration. Considered that the ammonia concentration in stormwater is usually very low [3], the sawdust should work effectively in term of removing ammonia in stormwater runoff.

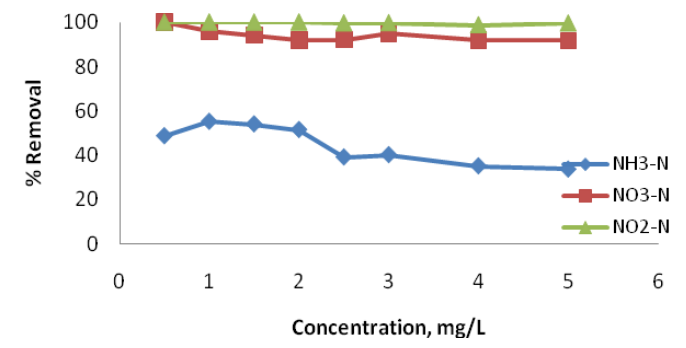

Fig.1. Effect of concentration on the removal of ammonia, nitrate, and nitrite as nitrogen by sawdust ( 20 gram sawdust, $200 \mathrm{~mL}$ water solution, $\mathrm{pH}$ 6-7) 
The percentage removal of nitrate as nitrogen was reached $100 \%$ at $0.5 \mathrm{mg} / \mathrm{L}$ within 21 hours and then was smoothly decreasing when the concentration increased. Nitrite as nitrogen was obtained $100 \%$ removal at $0.5 \mathrm{mg} / \mathrm{L}$ in 72 hours, whereas other concentrations were taking 96 hours for receiving equilibrium at almost $100 \%$ for all range of concentrations. These studies revealed that nitrate and nitrite as nitrogen are very well adsorbed onto sawdust at lower concentrations.

\section{B. Effect of Dosage Test}

Fig. 2 shows the removal of ammonia, nitrate, and nitrite as nitrogen as a function of adsorbent dosage. In general, the addition of the adsorbent dosage increased the percentage removal, which is due to enlarge in adsorbent surface area of the adsorbents. The maximum percentage of removal in each species was obtained at 20 gram of sawdust. It was found that $46 \%$ removal in 15 minutes, $93 \%$ removal in 15 minutes, and $99 \%$ removal within 43 hours were reached for $\mathrm{NH}_{3}-\mathrm{N}$, $\mathrm{NO}_{3}-\mathrm{N}$, and $\mathrm{NO}_{2}-\mathrm{N}$ respectively.

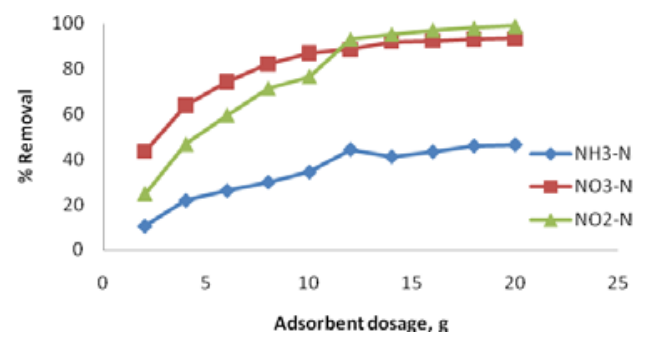

Fig. 2. Effect of sawdust dosage on removal of $\mathrm{NH}_{3}-\mathrm{N}, \mathrm{NO}_{3}-\mathrm{N}$, and $\mathrm{NO}_{2}-\mathrm{N}$ (200 mL of $1 \mathrm{mg} / \mathrm{L}$ concentration, $\mathrm{pH}$ 6-7)

\section{Adsorption Isotherm}

The adsorption isotherm is an important step of investigation to determine performance assessment of adsorption [22]. Table I lists the values of $q_{m}$ and $K_{L}$ which were calculated from the slope and intercept of the linear plots. The Langmuir adsorption maximum capacity, $q_{m}$ were $0.0647 \mathrm{mg} / \mathrm{g}$ and $0.0188 \mathrm{mg} / \mathrm{g}$ for nitrate and nitrite respectively. The value of Langmuir constants for nitrate and nitrite is very high $(\mathrm{K}>1)$. This high value indicates that nitrate and nitrite ions are strongly adsorbed onto the sawdust.

The variation of the adsorption intensity $\left(R_{L}\right)$ with the concentration of solution is exposed in Fig. 3. The $R_{L}$ value ranges for nitrate were 0.3923 to 0.8450 and nitrite value ranges were 0.0141 to 0.5190 . This parameter $\left(0<R_{L}<1\right)$ signifies that the sawdust is a proper adsorbent for the adsorption of nitrate and nitrite as nitrogen. Whereas, negative values for ammonia indicate the inadequacy of the isotherm model to explain the adsorption process [23].

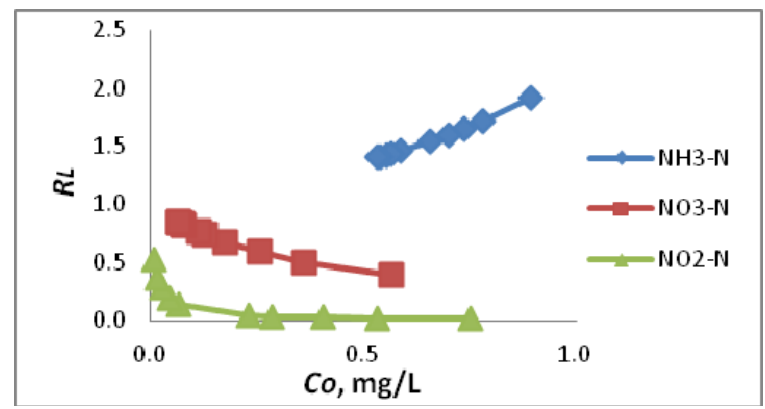

Fig. 3. Variation of adsorption intensity $\left(R_{\mathrm{L}}\right)$ for $\mathrm{NH}_{3}-\mathrm{N}, \mathrm{NO}_{3}-\mathrm{N}$, and $\mathrm{NO}_{2} \mathrm{~N}$

TABLE I: PARAMETERS OF THE LANGMUIR ISOTHERM FOR DIFFERENT ADSORBATES

\begin{tabular}{|c|c|c|c|c|c|c|c|}
\hline Adsorbates & Isotherm equation & R-square & $1 /\left(\mathrm{q}_{\mathrm{m}} \mathrm{K}_{\mathrm{L}}\right)$ & $\mathrm{q}_{\mathrm{m}} \mathrm{K}_{\mathrm{L}}$ & $1 / \mathrm{q}_{\mathrm{m}}$ & $\mathrm{q}_{\mathrm{m}}$ & $\mathrm{K}_{\mathrm{L}}$ \\
\hline $\mathrm{NH}_{3}-\mathrm{N}$ & $\mathrm{y}=164.19 \mathrm{x}-103.55$ & 0.9548 & 164.19 & 0.0061 & 103.5500 & 0.0097 & -0.6307 \\
\hline $\mathrm{NO}_{3}-\mathrm{N}$ & $\mathrm{y}=5.6327 \mathrm{x}+15.445$ & 0.9751 & 5.6327 & 0.1775 & 15.4450 & 0.0647 & 2.7420 \\
\hline $\mathrm{NO}_{2}-\mathrm{N}$ & $\mathrm{y}=0.5736 \mathrm{x}+53.162$ & 0.8049 & 0.5736 & 1.7434 & 53.1620 & 0.0188 & 92.6813 \\
\hline
\end{tabular}

TABLE II: PARAMETERS OF THE FREUNDLICH ISOTHERM FOR DIFFERENT ADSORBATES

\begin{tabular}{|c|c|c|c|c|c|c|}
\hline Adsorbates & Isotherm equation & R-square & $1 / \mathrm{n}$ & $\mathrm{n}$ & $\log \mathrm{K}$ & $\mathrm{K}$ \\
\hline $\mathrm{NH}_{3}-\mathrm{N}$ & $\mathrm{y}=0.0181 \mathrm{x}-4.7815$ & 0.9187 & 0.0181 & 55.2486 & -4.7815 & $1.65 \mathrm{E}-05$ \\
\hline $\mathrm{NO}_{3}-\mathrm{N}$ & $\mathrm{y}=0.0667 \mathrm{x}+0.0071$ & 0.9856 & 0.0667 & 14.9925 & 0.0071 & 1.0164 \\
\hline $\mathrm{NO}_{2}-\mathrm{N}$ & $\mathrm{y}=0.0189 \mathrm{x}+0.0118$ & 0.9231 & 0.0189 & 52.9101 & 0.0118 & 1.0275 \\
\hline
\end{tabular}

The Parameters of the Freundlich isotherm is shown in Table II. Values of $K$ and $n$ were calculated from the intersection and slope. In general, as the $K$ increases the adsorption capacity of the adsorbent increases. $K$ values showed that sawdust is more effective for removing $\mathrm{NO}_{2}-\mathrm{N}$. Comparing the correlation coefficients in both Langmuir and Freundlich, it was found that Freundlich model $\left(R^{2}=0.8324\right.$, 0.9856 , and 0.9231 for $\mathrm{NH}_{3}-\mathrm{N}, \mathrm{NO}_{3}-\mathrm{N}$ and $\mathrm{NO}_{2}-\mathrm{N}$ respectively) fits better than Langmuir model $\left(R^{2}=0.7963\right.$, 0.9751 , and 0.8049 for $\mathrm{NH}_{3}-\mathrm{N}, \mathrm{NO}_{3}-\mathrm{N}$ and $\mathrm{NO}_{2}-\mathrm{N}$ respectively). As the Freundlich type adsorption isotherm is an indication of surface heterogeneity of the adsorbent, this guide us to the conclusion that the surface of sawdust is made from small heterogeneous adsorption patches [24].

\section{CONCLUSION}

The capability of sawdust in adsorption $\mathrm{NH}_{3}-\mathrm{N}, \mathrm{NO}_{3}-\mathrm{N}$, and $\mathrm{NO}_{2}-\mathrm{N}$ has been investigated by batch experiments. From the results, it can be concluded that sawdust is a very good adsorbent due to its ability to remove $\mathrm{NH}_{3}-\mathrm{N}, \mathrm{NO}_{3}-\mathrm{N}$, and $\mathrm{NO}_{2}-\mathrm{N}$ from aqueous solution, especially at lower concentration. The percentage removal of $\mathrm{NH}_{3}-\mathrm{N}, \mathrm{NO}_{3}-\mathrm{N}$, and $\mathrm{NO}_{2}-\mathrm{N}$ was increased when the amount of adsorbent dosage increased. This was because of the increase in adsorbent surface area. From the variation of the adsorption intensity $\left(R_{L}\right)$, it can be concluded that the sawdust is an appropriate adsorbent for the adsorption of nitrate and nitrite as nitrogen. Equilibrium adsorption data fitted better with Freundlich isotherm for all adsorbates. From K-value of 
Freundlich model, sawdust is more effective for removing $\mathrm{NO}_{2}-\mathrm{N}$.

\section{REFERENCES}

[1] S. P. Seitzinger, R. W. Sanders, and R. Styles, "Bioavailability of DON from natural and anthropogenic sources to estuarine plankton," Limnology and Oceanography vol. 47 (2) pp.353-366, Jan 2002.

[2] C. W. Fetter, Contaminant Hydrogeology, Second Edition, Prentice Hall, Inc. New Jersey, 1999, ch 2.

[3] G. D. Taylor, T. D. Fletcher, T. H. F. Wong, P. F. Breen, and H. P. Duncan, "Nitrogen composition in urban runoff - implications for stormwater management," Water Research vol. 39, pp. 1982-1989, May 2005.

[4] J. M. Rodríguez-Maroto, F. García-Herruzo, A. García-Rubio, C. Gómez-Lahoz, C. Vereda-Alonso, "Kinetics of the chemical reduction of nitrate by zero-valent iron," Chemosphere vol. 74, pp. 804-809, Nov 2008.

[5] B. Gabel, R. Kozicki, U. Lahl, A. Podbielski, B. Stachel, and S. Struss, "Pollution of drinking water with nitrate," Chemosphere vol. 11, pp.1147-1154, June 1982.

[6] National Primary Drinking Water Standards, USEPA Standard EPA-816-F-03-016- 2003.

[7] S. D. Lloyd, T. D. Fletcher, T. H. F. Wong, and R. M. Wootton, "Assessment of Pollutant Removal in a Newly Constructed Bio-retention System," in Proc. 2nd Conf. South Pacific Stormwater Auckland, New Zealand, 2001, pp.20-30.

[8] M. Greenway and B. Lucas, "Improved media and plant species for long term sustainability of nutrient retention in bioretention systems," in Proc. National Conf. of the Stormwater Industry Association, 2010 pp.1-13.

[9] K. W. Cho, K.G. Song, J. W. Cho, T. G. Kim, K. H. Ahn, "Removal of nitrogen by a layered soil infiltration system during intermittent storm events," Chemosphere vol. 76 pp. 690-696, May 2009.

[10] S. A. Trowsdale and R. Simcock, "Urban stormwater treatment using bioretention," Journal of Hydrology vol. 397 pp. 167-174, Nov 2010

[11] N. Öztürk and T. E. Bekta, "Nitrate removal from aqueous solution by adsorption onto various materials," Journal of Hazardous Materials vol. B 112 pp. 155-162, May 2004.

[12] S. I. Lee, S. Y. Weon, C. W. Lee, and B. Koopman, "Removal of nitrogen and phosphate from wastewater by addition of bittern," Chemosphere vol. 51 pp. 265-271, Nov 2002.
[13] D. Karadag, Y. Koc, M. Turan, and B. Armagan, "Removal of ammonium ion from aqueous solution using natural Turkish clinoptilolite," Journal of Hazardous Materials vol. B 136, pp. 604-609, Jan 2006.

[14] Y. Wang, S. Liu, Z. Xu, T. Han, S. Chuan, and T. Zhu, “Ammonia removal from leachate solution using natural Chinese clinoptilolite," Journal of Hazardous Materials vol. B 136 pp. 735-740, Feb 2006.

[15] A. Ray, A. Selvakumar, and A. N. Tafuri, "Removal of selected pollutants from aqueous media by hardwood mulch," Journal of Hazardous Materials vol. B 136 pp. 213-218, Jan 2006.

[16] H. Kim, E. A. Seagren, and A. P. Davis. "Engineered bioretention for removal of nitrate from stormwater runoff," Water Environment Research vol. 754 pp. 355-367, July 2003.

[17] Z. Xuan, N. Chang, M. Wanielista, and F. Hossain, "Laboratory-scale Characterization of a green sorption medium for on-site sewage treatment and disposal to improve nutrient removal," Environmental Engineering Sciene vol. 274 pp. 301-312, Feb 2010.

[18] F. Hossain, N. Chang, and M. Wanielista, "Modeling Kinetics and Isotherms of Functionalized Filter Media for Nutrient Removal from Stormwater Dry Ponds," Environmental Progress \& Sustainable Energy vol. 293 pp. 319-333, Dec 2009.

[19] A. Shukla, Y. Zhang, P. Dubey, J. L. Margrave, and S. S. Shukla, "The role of sawdust in the removal of unwanted materials from water," Journal of Hazardous Materials vol. B 95 pp. 137-152, April 2002.

[20] A. Sari, M. Tuzen, D. Citak, and M. Soylak, "Equilibrium, kinetic and thermodynamic studies of adsorption of $\mathrm{Pb}$ (II) from aqueous solution onto Turkish kaolinite clay," Journal of Hazardous Materials vol. 149, pp. 283-291, March 2007.

[21] J. C. Crittenden, R. R. Trussell, D. W. Hand, K. J. Howe, and G. Tchobanoglous, Water Treatment: Principles and Design, 2nd ed. New Jersey, John Willey \& Sons, Inc, 2005, ch. 15 pp 1245-1357

[22] F. E. Bernardin, Jr, "Experimental design and testing of adsorption and adsorbates," in F. L. Slejko, Adsorption technology a step-by-step approach to process evaluation and application. New York, Marcel Dekker, Inc., 1985, ch. 3.

[23] K. R. Ramakrishna and T. Viraraghavan, "Dye removal using low cost adsorbents," Water Science Technology vol. 36 2-3 189, 1997.

[24] M. Ajmal, A. H. Khan, S. Ahmad, and A. Ahmad, "Role of sawdust in the removal of copper (II) from industrial wastes," Water Resources vol. 32, pp. 3085-3091, Feb 1998. 